\title{
Phylogenetic Relationships Among Global Populations of Pseudomonas syringae pv. actinidiae
}

\author{
J. R. Chapman, R. K. Taylor, B. S. Weir, M. K. Romberg, J. L. Vanneste, J. Luck, and B. J. R. Alexander
}

First, second, fourth, and seventh authors: Plant Health and Environment Laboratory, Ministry for Primary Industries, P.O. Box 2095, Auckland 1140, New Zealand; third author: Landcare Research, Private Bag 92170, Auckland 1142, New Zealand; fifth author: The New Zealand Institute for Plant and Food Research Ltd., Private Bag 3123, Hamilton 3240, New Zealand; and sixth author: Biosciences Research Division, Department of Primary Industries, 621 Burwood Highway, Knoxfield, Victoria 3180, Australia, and Department of Botany, La Trobe University, Victoria, 3086, Australia.

Current address of J. R. Chapman: Section for Zoonotic Ecology and Epidemiology, Linnaeus University, Kalmar SE-39182, Sweden.

Accepted for publication 30 July 2012.

\begin{abstract}
Chapman, J. R., Taylor, R. K., Weir, B. S., Romberg, M. K., Vanneste, J. L., Luck, J., and Alexander, B. J. R. 2012. Phylogenetic relationships among global populations of Pseudomonas syringae pv. actinidiae. Phytopathology 102:1034-1044.

Pseudomonas syringae pv. actinidiae, the causal agent of canker in kiwifruit (Actinidia spp.) vines, was first detected in Japan in 1984, followed by detections in Korea and Italy in the early 1990s. Isolates causing more severe disease symptoms have recently been detected in several countries with a wide global distribution, including Italy, New Zealand, and China. In order to characterize $P$. syringae pv. actinidiae populations globally, a representative set of 40 isolates from New Zealand, Italy, Japan, South Korea, Australia, and Chile were selected for extensive genetic analysis. Multilocus sequence analysis (MLSA) of housekeeping, type III effector and phytotoxin genes was used to eluci-

isolates worldwide. Four additional isolates, including one from China, for which shotgun sequence of the whole genome was available, were included in phylogenetic analyses. It is shown that at least four $P$. syringae pv. actinidiae MLSA groups are present globally, and that marker sets with differing evolutionary trajectories (conserved housekeeping and rapidly evolving effector genes) readily differentiate all four groups. The MLSA group designated here as Psa3 is the strain causing secondary symptoms such as formation of cankers, production of exudates, and cane and shoot dieback on some kiwifruit orchards in Italy and New Zealand. It is shown that isolates from Chile also belong to this MLSA group. MLSA group Psa4, detected in isolates collected in New Zealand and Australia, has not been previously described. $P$. syringae pv. actinidiae has an extensive global distribution yet the isolates causing widespread losses to the kiwifruit industry can all be traced to a single MLSA group, Psa3.
\end{abstract} date the phylogenetic relationships between $P$. syringae pv. actinidiae
The bacterium Pseudomonas syringae pv. actinidiae causes leaf spots, dieback, and canker of kiwifruit plants $(23,42,44,46)$ and is one of the most damaging kiwifruit pathogens. It has been shown to limit kiwifruit production in Japan and Korea $(24,44)$ and to cause severe vine losses in Italy $(3,19)$. P. syringae pv. actinidiae was first reported in Japan $(44,46)$ and has also been reported in South Korea $(23,25)$, China $(11,50)$, Italy (42), France (48), Portugal (5), Spain (1), Switzerland (12), Turkey (6), Chile (13), and Australia (14). In Italy, the bacterium has recently been associated with particularly severe disease symptoms, including leaf wilting; twig and cane dieback; cankers on canes, leaders, and trunks; plant wilting; and production of an oozing red or white exudate $(4,18,49)$. Although $P$. syringae pv. actinidiae was detected in Italy for the first time in 1992 (42), severe epidemics of bacterial canker were only noted in 2008 in the provinces of Latina and Ravenna $(18,19)$. These symptoms were the result of an outbreak of $P$. syringae pv. actinidiae that commenced in these regions in $2007(3,4,18)$. Balestra et al. (3) found that Actinidia chinensis (gold-fleshed kiwifruit) cultivars were mainly affected, although the bacterium was also found occasionally on $A$.

Corresponding author: J. Chapman; E-mail address: joanne.chapman@lnu.se

* The $\boldsymbol{e}$-Xtra logo stands for "electronic extra" and indicates that the online version contains one supplemental text file, five supplemental tables, and three supplemental figures.

http://dx.doi.org/10.1094/PHYTO-03-12-0064-R

(C) 2012 The American Phytopathological Society deliciosa (green-fleshed kiwifruit) cultivars. A. chinensis 'Hort $16 \mathrm{~A}$ ' and 'Jin Tao' were most severely affected, with disease incidence up to $70 \%$ in Hort $16 \mathrm{~A}$ (3). P. syringae pv. actinidiae was first detected in New Zealand in November 2010 (16), and a biosecurity response was initiated by the Ministry for Primary Industries (formerly Ministry of Agriculture and Forestry [MAF]). As part of this response, the bacterium was isolated from symptomatic leaves collected from kiwifruit orchards located across the North and upper South Islands of New Zealand (10; J. L. Vanneste et al., unpublished data).

The global pattern of genotypic variation of $P$. syringae pv. actinidiae is unknown but genetic differences between populations have recently been observed. Ferrante and Scortichini (19) characterized $P$. syringae pv. actinidiae populations from Italy and Japan via sequencing of four housekeeping genes, repetitivesequence polymerase chain reaction (rep-PCR), and presence or absence of effector and toxin genes. They found that $P$. syringae pv. actinidiae isolates collected in Italy in 1992 and in Japan in 1984 were genetically identical but that these isolates were genetically distinct from isolates collected in the Latina and Ravenna regions of Italy during the severe outbreaks of 2008 and 2009. Vanneste et al. (49) further showed that, at the citrate synthase (cts) gene, a single isolate from Korea was genetically identical to the Italian (1992) and Japanese (1984) isolates, and these isolates could be differentiated from the Italian (2008-09) isolates. More recently, the number of isolates characterized for cts variation and rep-PCR profile was extended to 15 from Japan and Korea and 40 from Italy (2008-09 outbreak), and two 
haplotypes were again detected, whereby Japanese and Korean isolates were grouped as one haplotype and Italian (2008-09 outbreak) isolates were considered a second haplotype (47). Mazzaglia et al. (31) also compared strains from Japan, Korea, and Italy using rep-PCR, IS50-PCT, and random amplified polymorphic DNA techniques and found no genetic differentiation between 44 Italian isolates collected during the 2008-09 outbreak but that these Italian isolates could be genetically differentiated from Asian isolates using all three methods. Recently, genome sequencing of $P$. syringae pv. actinidiae isolates has further aided in the characterization of strains. Marcelletti et al. (30) found that genomic sequences for one Japanese and one Italian 1992 isolate were highly similar but that there were significant genetic changes between these isolates and an Italian 2008-09 isolate (30). Mazzaglia et al. (32) greatly expanded this analysis by including isolates from Korea, China, Portugal, France, and Spain. They found two distinct $P$. syringae pv. actinidiae lineages - a Japanese/Korean lineage that also included isolates from the early Italian (1992) $P$. syringae pv. actinidiae outbreak and a European/Chinese lineage comprising isolates from Italy, Spain, France, and Portugal—as well as isolates from New Zealand and China. Taken together, these results suggest that at least two populations of $P$. syringae pv. actinidiae are present globally: the population found in Japan, Korea, and Italy (1992 outbreak) and the population found in Italy during the 2008-09 outbreak. To date, no molecular characterization work has been completed on isolates from Chile and Australia.

In order to examine and better understand the levels of genetic diversity and phylogenetic relationships within and between $P$. syringae pv. actinidiae populations globally, isolates from different areas of the world were characterized. Forty isolates were collected from Japan, Korea, Italy, Chile, New Zealand, and Australia. All isolates were sequenced at 7 housekeeping genes and PCR typed at 11 effector genes, 2 phytotoxin genes, and 1 putative magnesium transporter gene. Housekeeping, effector, and phytotoxin genes were chosen because they have been previously typed in $P$. syringae (including $P$. syringae pv. actinidiae) and because they may have differing evolutionary trajectories $(19,40)$.

Housekeeping genes form part of the core genome, are generally essential for survival due to their role in metabolic functions, are widely distributed in the genome, have low propensity for horizontal genetic exchange, and are generally selectively neutral or under purifying selection. This class of genes has been well characterized in other $P$. syringae pathovars, whereby multilocus sequence analysis (MLSA) of fragments of several housekeeping genes has been used for phylogenetic reconstruction. For example, Sarkar and Guttman (40) sequenced 60 isolates of 21 pathovars at all seven $P$. syringae housekeeping genes used in the present study; Hwang et al. (21) sequenced 95 isolates of 26 pathovars at four housekeeping genes ( $r p o D, g y r B$, cts, and gapA); Bull et al. (8) used these same four genes to sequence 54 $P$. syringae pathovars and three $P$. cannabina pathovars, all of which were type or pathotype strains; and Parkinson et al. (36) sequenced a total of 67 pathovars (all currently known type strains in the $P$. syringae species complex) for a single housekeeping gene, $r p o D$. All of these studies revealed that $P$. syringae pv. actinidiae is part of phylogroup 1. A number of different hosts are exploited by other $P$. syringae pathovars within this phylogroup, including cucumber, cabbage, celery, tea, passionfruit, tomato, Prunus spp., and a number of ornamental plants.

Type III effector genes (hop, hrp, and $a v r$ genes) occur in the "flexible" part of the $P$. syringae genome and allow the bacteria to interact with their plant hosts. This part of the genome largely evolves via horizontal genetic exchange, which allows rapid gain and loss of genes (21). These genes encode proteins that are injected into host plant cells by the type III secretion system (27) and have a role in pathogen virulence (41). The expression patterns and genetic variation of type III effectors have been well characterized in $P$. syringae $(9,21,41)$, and their presence or absence has been assessed for populations of $P$. syringae pv. actinidiae from Italy and Asia $(18,19)$.

The phytotoxins phaseolotoxin and coronatine are virulence factors which act by blocking plant defense responses and induce chlorosis $(7,21)$. Both phytotoxins are synthesized by clusters of linked genes which form pathogenicity islands; phaseolotoxin is synthesized by the Pht cluster and coronatine by the cor cluster. Not all $P$. syringae pathovars synthesize these phytotoxins $(7,21)$, and differential synthesis has also been detected between populations of $P$. syringae pv. actinidiae. Shim Han et al. (45) detected coronatine in Korean but not Japanese isolates, and phaseolotoxin in Japanese but not Korean isolates; Ferrante and Scortichini (19) detected phaseolotoxin in Japanese isolates and Italian isolates from 1992 but not in Italian isolates from 200809; coronatine was not detected in these isolates either.

The objective of this study was to elucidate the genetic relationships among populations of $P$. syringae pv. actinidiae isolates present in Europe, Australasia, South America, and Asia. Understanding the global population structure of $P$. syringae pv. actinidiae isolates will help inform disease management and will provide a foundation for further population studies in countries where $P$. syringae pv. actinidiae is found.

\section{MATERIALS AND METHODS}

$\boldsymbol{P}$. syringae pv. actinidiae isolate selection. In total, 40 isolates-from New Zealand $(n=11)$, Italy 1992 outbreak $(n=$ 2), Italy 2008-09 outbreak $(n=10)$, Japan $(n=5)$, Korea $(n=3)$, Chile $(n=5)$, and Australia $(n=4)$-were chosen for in-depth molecular characterization, in order to cover the main geographic regions of the world currently known to have $P$. syringae pv. actinidiae; namely, Europe, Asia, South America, and Australasia (Table 1). Overseas isolates were sourced from international culture collections or from individual $P$. syringae pv. actinidiae researchers in those countries (Table 1). Isolates were cultured on King's medium B (KB) (22) and incubated at $25^{\circ} \mathrm{C}$ for 2 days. Bacterial cultures were visually checked for purity and genomic DNA was extracted directly from colonies using a commercially available kit (Blood and Tissue Kit; Qiagen, Hilden, Germany).

Preliminary characterization of $P$. syringae pv. actinidiae in New Zealand (sequencing of $c t s$, gyrB, and $h r p K 1$ genes using the methods described below) suggested that two MLSA groups (haplotypes or populations) are present (10; J. L. Vanneste et al., unpublished data). Isolates of each of these two New Zealand MLSA groups were selected for further characterization. We have named the two New Zealand MLSA groups Psa3 and Psa4 (see also Results and Discussion for further details on naming of MLSA groups). Six Psa3 isolates were obtained from symptomatic kiwifruit leaves from orchards in the Bay of Plenty region (the predominant region of New Zealand currently infected with Psa3) and five Psa4 isolates were obtained from symptomatic leaves within orchards from a wider geographic distribution (Fig. 1). Isolates used in this study were deposited in the International Collection of Mircoorganisms from Plants (ICMP) culture collection (Table 1), with the exception of one Australian and four Italian isolates for which DNA samples were obtained for the current research. Full strain details for ICMP isolates can be found at http://www.landcareresearch.co.nz/databases/icmp.

Bacterial isolation from infected tissue. Symptomatic kiwifruit leaves, collected from orchards within New Zealand, were surface sterilized with $70 \%$ ethanol and allowed to air dry. Small pieces of leaf tissue were removed aseptically from the margins of angular lesions symptomatic of $P$. syringae pv. actinidiae, and ground in bacteriological saline $(0.85 \%$ [wt/vol] $\mathrm{NaCl})$, then left at room temperature $\left(\right.$ c. $20^{\circ} \mathrm{C}$ ) for $10 \mathrm{~min}$. Aliquots of the macerated leaf tissue were streaked onto $\mathrm{KB}$ and incubated at $25^{\circ} \mathrm{C}$ 
overnight. Those bacterial colonies, presumed to be $P$ syringae pv. actinidiae based on morphological characteristics (creamcolored colonies with variable fluorescence) (16), were subcultured onto $\mathrm{KB}$ to obtain single colonies. The identity of these $P$. syringae pv. actinidiae-presumptive colonies was confirmed by PCR using the specific primers for $P$. syringae pv. actinidiae developed by Rees-George et al. (37), Koh and Nou (24), and Scortichini et al. (43), as well as LOPAT, Biolog, and pathogenicity testing (Supplemental Tables S1 and S2) and gene sequencing (see below). After confirmation of their identity, bacterial isolates were stored at $-80^{\circ} \mathrm{C}$ in glycerol at a final concentration of $15 \%$.

DNA extraction, PCR amplification, and sequencing. DNA was extracted from a loopful of bacteria obtained from pure cultures growing on KB using a commercially available kit (Blood and Tissue Kit; Qiagen) following the manufacturer's instructions. DNA was eluted in $50 \mu \mathrm{l}$ of elution buffer and stored at $-80^{\circ} \mathrm{C}$ until required for downstream applications. PCR reactions were performed on GeneAmp 9700 thermal cyclers (Applied Biosystems; Foster City, CA) following published protocols (Supplemental Table $\mathrm{S} 3$ provides relevant references). PCR products were purified using a commercially available kit (QIAquick PCR Purification Kit; Qiagen) according to the manufacturer's instructions and sequenced in forward and reverse directions by a commercial DNA-sequencing service (Ecogene, Auckland, NZ) using an Applied Biosystems 3730xl Genetic Analyzer.

MLSA. Seven housekeeping genes, most with key roles in carbohydrate metabolism, were amplified and sequenced using the primers described by Sarkar and Guttman (40). PCR was carried out in a total volume of $20 \mu \mathrm{l}$ containing $1 \times$ PCR buffer (20 mM Tris- $\mathrm{HCl}[\mathrm{pH} 8.4]$ and $50 \mathrm{mM} \mathrm{KCl}$ ), $2 \mathrm{mM} \mathrm{MgCl}_{2}$, the four deoxynucleoside triphosphates (dNTPs; $0.2 \mathrm{mM}$ each), 0.05 U of Platinum Taq DNA polymerase (Invitrogen, Carlsbad, CA), $0.25 \mu \mathrm{mol}$ each primer, and 20 to $50 \mathrm{ng}$ of template DNA. The

TABLE 1. List of isolates used in this study

\begin{tabular}{|c|c|c|c|c|c|c|c|c|}
\hline Isolate name ${ }^{a}$ & Alternative name & Host & Isolated by & $\begin{array}{l}\text { Country of } \\
\text { origin }\end{array}$ & Region & $\begin{array}{l}\text { Year of } \\
\text { isolation }\end{array}$ & $\begin{array}{l}\text { ICMP } \\
\text { number }\end{array}$ & $\begin{array}{l}\text { MLSA } \\
\text { group }^{b}\end{array}$ \\
\hline T10_04758 & $\cdots$ & $\begin{array}{l}\text { Actinidia } \\
\text { chinensis }\end{array}$ & R. Taylor & New Zealand & Te Puke, Bay of Plenty & 2010 & ICMP 18708 & Psa3 \\
\hline T10_04782 & $\ldots$ & A. chinensis & R. Taylor & New Zealand & Te Puke, Bay of Plenty & 2010 & ICMP 18801 & Psa3 \\
\hline T10_05454 & $\ldots$ & A. deliciosa & R. Taylor & New Zealand & Rangiuru, Bay of Plenty & 2010 & ICMP 19075 & Psa3 \\
\hline T10_06115 & $\ldots$ & A. deliciosa & R. Taylor & New Zealand & Rangiuru, Bay of Plenty & 2010 & ICMP 18884 & Psa3 \\
\hline T11_0918 & $\ldots$ & A. deliciosa & R. Taylor & New Zealand & Pukehina, Bay of Plenty & 2011 & ICMP 19076 & Psa3 \\
\hline T10_05815 & $\ldots$ & A. deliciosa & R. Taylor & New Zealand & Te Puke, Bay of Plenty & 2010 & ICMP 19101 & Psa3 \\
\hline T10_04976 & $\ldots$ & A. chinensis & R. Taylor & New Zealand & Pongakawa, Bay of Plenty & 2010 & ICMP 19074 & Psa4 \\
\hline T10_05188 & $\ldots$ & A. chinensis & M. Romberg & New Zealand & Rangiuru, Bay of Plenty & 2010 & ICMP 18804 & Psa4 \\
\hline T10_05163 & $\ldots$ & A. chinensis & M. Romberg & New Zealand & Hastings, Hawke's Bay & 2010 & ICMP 18803 & Psa4 \\
\hline T10_05195 & $\ldots$ & A. deliciosa & M. Romberg & New Zealand & Golden Bay, Nelson & 2010 & ICMP 18883 & Psa4 \\
\hline T10_05196 & $\ldots$ & A. chinensis & M. Romberg & New Zealand & Motueka, Nelson & 2010 & ICMP 18882 & Psa4 \\
\hline NCPPB $3739^{\circ}$ & Kw11 & A. chinensis & Y. Takikawa & Japan & Shizuoka & 1984 & ICMP 9617 & Psa1 \\
\hline MAFF 302091 & FTRS L 1 & A. deliciosa & K. Takanashi & Japan & Kanagawa & 1984 & ICMP 19069 & Psa1 \\
\hline MAFF 302143 & Kw 4 & A. deliciosa & N. Kita & Japan & Kanagawa & 1987 & ICMP 19070 & Psa1 \\
\hline MAFF 302145 & Wa1 & A. deliciosa & N. Kita & Japan & Wakayama & 1988 & ICMP 19068 & Psa1 \\
\hline ICMP 9855 & Kw41 & A. deliciosa & Y. Takikawa & Japan & Shizuoka & 1984 & ICMP 9855 & Psal \\
\hline KACC 10584 & $\ldots$ & A. chinensis & S.J. Go & Korea & Jeonnam & 1997 & ICMP 19072 & Psa2 \\
\hline KACC 10594 & $\ldots$ & A. chinensis & S.J. Go & Korea & Jeonnam & 1998 & ICMP 19073 & Psa2 \\
\hline KACC 10754 & $\ldots$ & A. chinensis & S.J. Go & Korea & Jeonnam & 1997 & ICMP 19071 & Psa2 \\
\hline Psa1A & $\ldots$ & A. deliciosa & V. Caro & Chile & Maule & 2010 & ICMP 19438 & Psa3 \\
\hline Psa1B & $\ldots$ & A. deliciosa & V. Caro & Chile & Maule & 2010 & ICMP 19439 & Psa3 \\
\hline 287A63 & $\ldots$ & A. deliciosa & V. Caro & Chile & Maule & 2010 & ICMP 19457 & Psa3 \\
\hline 286532 & $\ldots$ & A. deliciosa & V. Caro & Chile & Maule & 2010 & ICMP 19455 & Psa3 \\
\hline 2871B5 & $\ldots$ & A. deliciosa & V. Caro & Chile & Maule & 2010 & ICMP 19456 & Psa3 \\
\hline T11_01581B & DAR65833 & A. chinensis & R. Floyd & Australia & Western Australia & 1990 & ICMP 19486 & Psa4 \\
\hline T11_01369A & $\ldots$ & A. chinensis & J. Luck & Australia & Victoria & 2011 & ICMP 19440 & Psa4 \\
\hline T11_01395A & $\ldots$ & A. chinensis & J. Luck & Australia & Victoria & 2011 & ICMP 19441 & Psa4 \\
\hline 28830 & $\ldots$ & A. chinensis & S. Doughty & Australia & Victoria & 2011 & N/A & Psa4 \\
\hline NCPPB 3873 & ISPAVE-B-019 & A. deliciosa & M. Scortichini & Italy & Latina & 1992 & ICMP 19091 & Psa1 \\
\hline NCPPB 3871 & ISPAVE-B-020 & A. deliciosa & M. Scortichini & Italy & Latina & 1992 & ICMP 19090 & Psa1 \\
\hline I-Psa Z & $\ldots$ & A. chinensis & G. Balestra & Italy & Latina & 2008 & N/A & Psa3 \\
\hline I-Psa 8 & $\ldots$ & A. chinensis & G. Balestra & Italy & Latina & 2008 & N/A & Psa3 \\
\hline CRA-FRU 10.22 & $\ldots$ & A. chinensis & M. Scortichini & Italy & Latina & 2008 & N/A & Psa3 \\
\hline CRA-FRU 8.76 & $\ldots$ & A. deliciosa & M. Scortichini & Italy & $\ldots$ & 2009 & N/A & Psa3 \\
\hline CRA-FRU 11.40 & $\ldots$ & A. deliciosa & M. Scortichini & Italy & Rome & 2010 & ICMP 18743 & Psa3 \\
\hline CRA-FRU 11.41 & $\ldots$ & A. deliciosa & M. Scortichini & Italy & Rome & 2010 & ICMP 18744 & Psa3 \\
\hline CRA-FRU 11.42 & $\ldots$ & A. chinensis & M. Scortichini & Italy & Latina & 2010 & ICMP 18745 & Psa3 \\
\hline CRA-FRU 11.43 & $\ldots$ & A. chinensis & M. Scortichini & Italy & Latina & 2010 & ICMP 18746 & Psa3 \\
\hline I.6.5.10.4-4 & $\ldots$ & A. chinensis & J. Vanneste & Italy & Latina & 2010 & ICMP 19078 & Psa3 \\
\hline I.27.4.10.D1 & $\ldots$ & A. chinensis & J. Vanneste & Italy & Latina & 2010 & ICMP 19079 & Psa3 \\
\hline CH2010-6 $6^{\mathrm{d}}$ & $\ldots$ & A. chinensis & $\ldots$ & China & Shaanxi province & 2010 & N/A & Psa3 \\
\hline PA 459e & CFBP 5097 & A. chinensis & M. Goto & Japan & $\ldots$ & 1988 & N/A & Psa1 \\
\hline CRA-FRU $8.43^{\mathrm{f}}$ & $\ldots$ & A. chinensis & M. Scortichini & Italy & Latina & 2008 & N/A & Psa3 \\
\hline CFBP $7286^{\mathrm{g}}$ & PSAH108 & A. chinensis & G. Balestra & Italy & Latina & 2008 & N/A & Psa3 \\
\hline
\end{tabular}

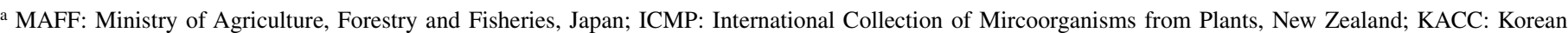

Agricultural Culture Collection, Korea; NCPBB: National Collection of Plant Pathogenic Bacteria, UK; CFBP: French Collection of Plant Associated Bacteria.

b MLSA = multilocus sequence analysis.

c This isolate is the pathotype of $P$. syringae pv. actinidiae.

${ }^{d}$ This isolate has been whole genome shotgun sequenced and sequences from GenBank (AGUH01000000.1) were used in this study (32).

e This isolate has been whole genome shotgun sequenced and sequences from GenBank (AGNQ01000000.1) were used in this study (32).

$\mathrm{f}$ This isolate has been whole genome shotgun sequenced and sequences from GenBank (AFTG01000000.1) were used in this study (30).

$\mathrm{g}$ This isolate has been whole genome shotgun sequenced and sequences from GenBank (AGNO01000000.1) were used in this study (324). 
genes sequenced were aconitate hydratase B (acn; GenBank accession numbers JN683379 to JN683397, JQ836583 to JQ836586, and JX287922 to JX287938), $\sigma$ factor 70 (rpoD; GenBank accession numbers JN683398 to JN683416, JQ836579 to JQ836582, and JX287905 to JX287921), phosphoglucoisomerase (pgi; GenBank accession numbers JN683417 to JN683435, JQ836650 to JQ836653, and JX288106 to JX288122), phosphofructokinase ( $p f k$; GenBank accession numbers JN683436 to JN683454, JQ836646 to JQ836649, and JX288089 to JX288105), DNA gyrase B ( gyrB; GenBank accession numbers JN683455 to JN683473, JQ836624 to JQ836627, and JX288022 to JX288038), glyceraldehyde-3-phosphate dehydrogenase (gapA; GenBank accession numbers JN683474 to JN683492, JQ836620 to JQ836623, and JX288005 to JX288021), and citrate synthase (cts, also known as gltA; GenBank accession numbers JN683493 to JN683511, JQ836616 to JQ836619, and JX287988 to JX288004). A list of the individual GenBank number assigned to each gene plus isolate combination can be found as Supplemental Table S4. For each isolate, the combination of alleles at each locus was used to assign it to an MLSA group (33).

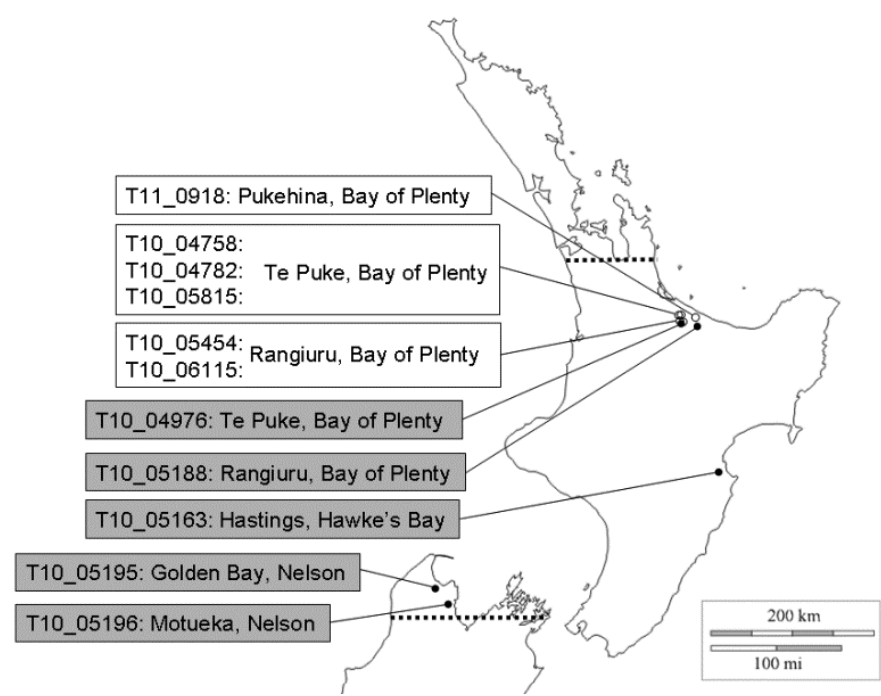

Fig. 1. Map of New Zealand showing origin of Pseudomonas syringae pv. actinidiae isolates used in this study. Open dots connecting clear boxes are Psa3 isolates, black dots connecting gray boxes are Psa4 isolates. Dashed lines denote the current northern and southern limits of $P$. syringae pv. actinidiae spread in New Zealand.
Effector gene typing. The presence of 11 putative effector genes were detected using the primers described by Ferrante et al. (17) and Ferrante and Scortichini (19), and amplification products were sequenced. These loci were chosen to allow for direct comparisons with previous analyses of $P$. syringae pv. actinidiae population diversity $(17,19)$ and to provide a contrast with more slowly evolving housekeeping genes. PCR was carried out in a total volume of $20 \mu \mathrm{l}$ containing $2 \times$ GoTaq Green Master Mix (Promega Corp., Madison, WI), $0.25 \mu \mathrm{mol}$ each primer, and 20 to $50 \mathrm{ng}$ of template DNA. DNA sequences have been deposited in GenBank (accession numbers JN683512 to JN683601, JN683605 to JN683623, JQ836587 to JQ836592, JQ836628 to JQ836645, JX287939 to JX287987, and JX288039 to JX288088; a list of the individual GenBank numbers assigned to each gene plus isolate combination can be found as Supplemental Table S4).

Phytotoxin gene detection. One locus in the cor cluster and three loci in the Pht gene cluster were amplified to detect the presence of coronatine and phaseolotoxin genes, respectively (Table 2). PCR was carried out in a total volume of $20 \mu \mathrm{l}$ containing $1 \times$ PCR buffer $(20 \mathrm{mM}$ Tris- $\mathrm{HCl}[\mathrm{pH} 8.4]$ and $50 \mathrm{mM}$ $\mathrm{KCl}), 2.5 \mathrm{mM} \mathrm{MgCl}_{2}$, the four dNTPs (0.2 mM each), $0.05 \mathrm{U}$ of Platinum Taq DNA polymerase (Invitrogen), $0.25 \mu \mathrm{mol}$ each primer, and 20 to $50 \mathrm{ng}$ of template DNA. Coronatine sequences have been deposited in GenBank (accession numbers JN683602 to JN683604).

Analysis of published $P$. syringae pv. actinidiae genome sequences. In addition to the 40 isolates that were directly sequenced for this article, four additional $P$. syringae pv. actinidiae isolates for which whole genome sequences were available in GenBank were included in phylogenetic analyses. The isolates included (Table 1) were (i) CH2010-6, from the Shaanxi province of China (accession numbers AGUH01000001 to AGUH01000563) (34); (ii) PA459 from Japan (accession numbers AGNQ01000000 to AGNQ01000730) (34), (iii) CRA-FRU 8.43 from Italy (2008-09 outbreak, accession numbers AFTG01000001 to AFTG01000585) (30), and (iv) CFBP 7286 from Italy (2008-09 outbreak, accession numbers AGNO01000000 to AGNO01000462) (32). All shotgun sequences for each isolate were BLAST searched for the 15 sequenced genes listed in Table 2, and the corresponding genetic sequence for these isolates for each gene was included in all phylogenies.

Phylogenetic analysis. Geneious 5.5.6 (Biomatters, Auckland, New Zealand) was used for DNA sequence and initial phylogenetic analyses. Terminal sequences were trimmed to remove primer sequences. A single representative of each $P$. syringae pathovar sequenced by Sarkar and Guttman (40) was selected,

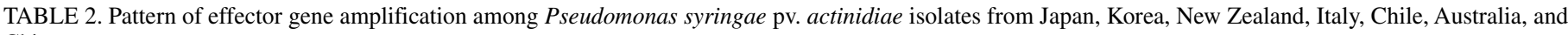
China $^{\mathrm{a}}$

\begin{tabular}{|c|c|c|c|c|c|c|c|c|c|}
\hline \multirow[b]{3}{*}{ Gene name } & \multicolumn{9}{|c|}{ Country of origin, MLSA group } \\
\hline & Japan & Italy (1992 outbreak) & Korea & New Zealand & Italy (2008-09 outbreak) & Chile & New Zealand & Australia & China \\
\hline & Psa1 & Psal & Psa2 & Psa3 & Psa3 & Psa3 & Psa4 & Psa4 & Psa3 \\
\hline avrPtol & - & - & - & - & - & - & - & - & - \\
\hline avrD1 & + & + & + & + & + & + & - & - & + \\
\hline avrE1 & + & + & + & + & + & + & + & + & + \\
\hline hopA1 & - & - & - & + & + & + & + & + & + \\
\hline hopCl & - & - & - & - & - & - & - & - & - \\
\hline hopD1 & + & + & + & + & + & + & + & + & + \\
\hline hopF2 & - & - & - & - & - & - & - & - & - \\
\hline hopG1 & - & - & - & - & - & - & - & - & - \\
\hline hrpK1 & + & + & + & + & + & + & + & + & + \\
\hline hopAF1 & - & - & \pm & - & - & - & + & + & - \\
\hline hopAN1 & + & + & + & + & + & + & + & + & + \\
\hline corAlike & + & + & + & + & + & + & + & + & + \\
\hline Phaseolotoxin & + & + & - & - & - & - & - & - & - \\
\hline Coronatine & - & - & + & - & - & - & - & - & - \\
\hline
\end{tabular}

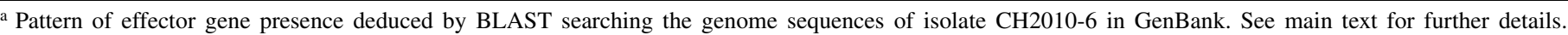
MLSA = multilocus sequence analysis. + symbol indicates tht the gene is present, whereas - symbol indicates that the gene was not detected by PCR 
and DNA sequences for all seven housekeeping genes for that isolate were downloaded from GenBank. For the housekeeping and effector classes of genes, concatenated trees were constructed by assembling amplification products of uniform length per isolate in the same order for all isolates. The model of DNA evolution for each gene was estimated using MrModeltest 2.3 (34) (Supplemental Table S5). The genes were concatenated in alphabetical order and a separate partition was created for each gene and run in MrBayes 3.2.1 (39) for $1 \times 10^{7}$ generations; the burn-in was set at $25 \%$ after examining convergence diagnostics in MrBayes and Tracer (http://tree.bio.ed.ac.uk/software/tracer/). Posterior probabilities $<0.5$ were collapsed to polytomies to form $50 \%$-majority-rule consensus trees. Effector and housekeeping genes were treated separately; where effector genes were absent in some strains, these were analyzed using gap symbols (-) for the entire gene. Full alignments and trees are available in TreeBASE, study ID S11869.

$\mathrm{Ka} / \mathrm{Ks}$ ratios were calculated using the KaKs_Calculator (51), freely available for download (http://evolution.genomics.org.cn/ software.htm). Model averaged $\mathrm{Ka} / \mathrm{Ks}$ ratios, denoted here as $\mathrm{Ka} / \mathrm{Ks}_{\mathrm{MA}}$, after AICc selection of the best model from 14 candidate models (51), are reported.

\section{RESULTS}

Multilocus sequence analysis. Moderate levels of housekeeping gene sequence variation between isolates from different geographic regions of the world were detected, and four MLSA groups are clearly discernible (Fig. 2). We have named these MLSA groups as follows: Psa1 for isolates from Japan and Italy
(1992 outbreak); Psa2 for isolates from Korea; Psa3 for isolates from Italy (2008-09 outbreak), New Zealand, Chile, and China; and Psa4 for isolates from New Zealand and Australia (Table 1). The rationale for this naming scheme is expanded upon in the Discussion.

For each of the seven housekeeping genes, the six New Zealand Psa3 isolates were genetically identical to each other and to the 12 isolates from Italy (2008-09 outbreak), the five isolates from Chile, and the Chinese isolate. The six isolates from Japan were genetically identical to the two isolates from the 1992 outbreak of $P$. syringae pv. actinidiae in Italy (Psa1), and these isolates were genetically very similar to the three Korean isolates (Psa2). Psa1 and Psa2 isolates were closely related to the New Zealand, Italian, Chilean, and Chinese Psa3 isolates (5 and 10 single-nucleotide proteins [SNPs] across all 4,298 bp of the concatenated alignment separate the Psa1 and Psa2 isolates, respectively, from the Psa3 isolates). The four Australian and five New Zealand Psa4 isolates were genetically distinct from all other isolates (Fig. 2). The long branch length between the Psa3 and Psa4 isolates represents 1.2\% genetic divergence (52 SNPs across all 4,298 bp of the concatenated alignment of seven genes). In all, 49 of the SNPs separating Psa4 from the other three MLSA groups were synonymous substitutions and 3 were nonsynonymous substitutions. In the gene $p f k$, a valine residue at amino acid position 110 has changed to an alanine residue in two isolates from Japan (MAFF 302143 and ICMP 9855). In the gene rpoD, two nonsynonymous substitutions differentiate the Psa4 isolates from all other isolates: a glutamic acid to aspartic acid change at residue 68 and an isoleucine to valine change at residue 94 . The $\mathrm{Ka} / \mathrm{Ks}_{\mathrm{MA}}$ ratio for rpoD was $0.18(P=0.04)$, suggesting selection pressure to con-

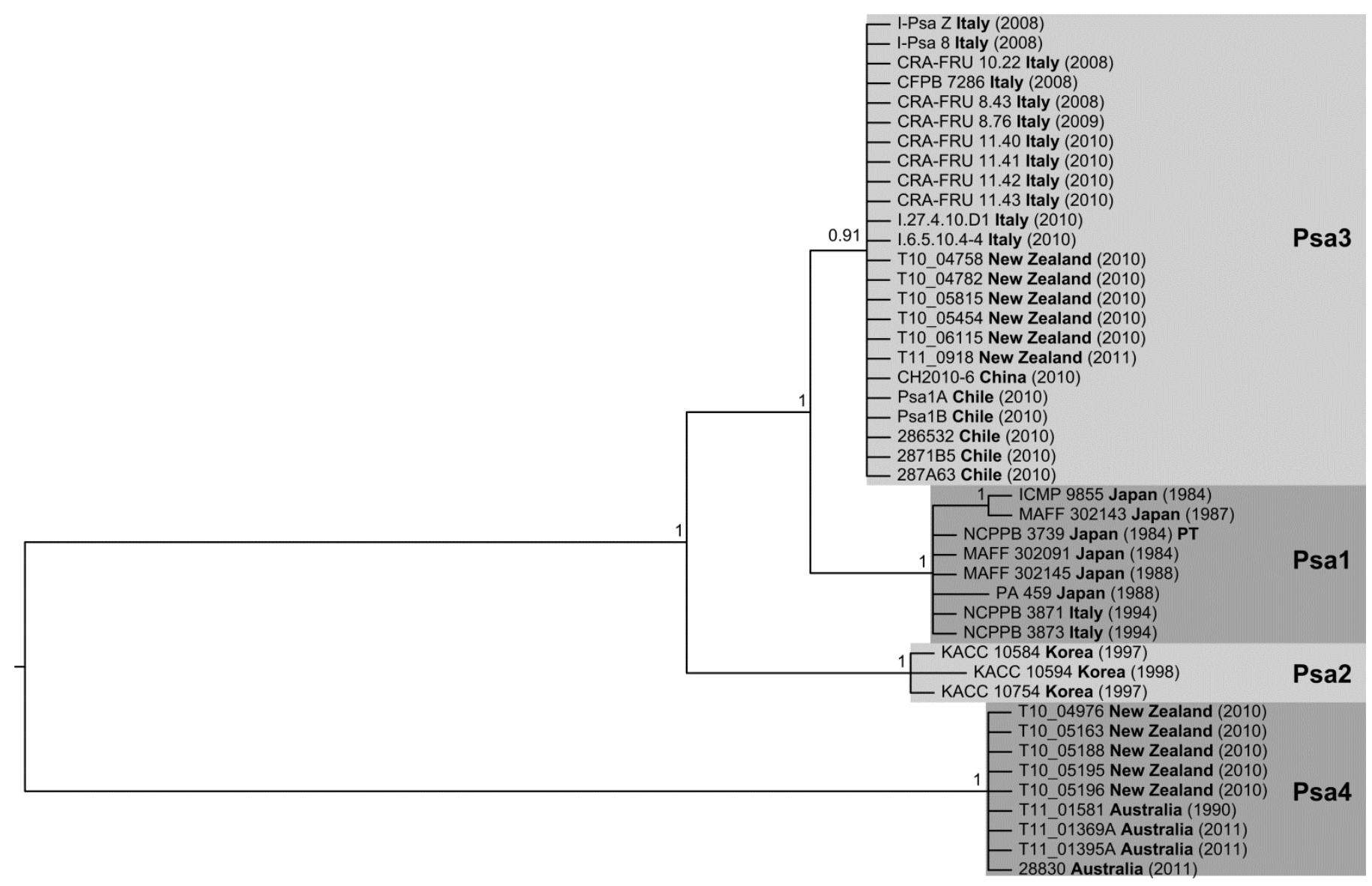

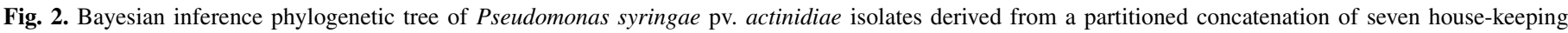

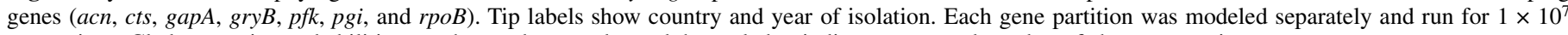
generations. Clade posterior probabilities are shown above nodes and the scale bar indicates expected number of changes per site. 
serve secondary structure for this gene (purifying selection). There was distinct genetic differentiation between Psa3 and Psa4 isolates for every individual housekeeping gene (Supplemental Figure S1).

A phylogeny of representative $P$. syringae pathovar isolates amplified at the same seven housekeeping genes by Sarkar and Guttman (40) and the $P$. syringae pv. actinidiae isolates amplified in this study shows that all $44 P$. syringae pv. actinidiae isolates considered in this study clearly fall within phylogroup I, as expected for $P$. syringae pv. actinidiae (Fig. 3). Interestingly, Psa1, Psa2, and Psa3 isolates appear to share a closer genetic relationship with $P$. syringae pv. theae than with Psa4.

Effector gene typing. Sequence analysis revealed that the Ferrante and Scortichini (19) primers for hopB1 do not amplify this effector gene. Instead, they amplify a conserved hypothetical protein that appears to belong to the CorA superfamily and, therefore, may be involved in $\mathrm{Mg}^{2+}$ transportation. We have named this gene corA-like for the purposes of this article, to distinguish it from true effector genes. We excluded this locus from phylogenetic reconstructions of effector genes (see below) but include a phylogenetic tree for this locus as Supplemental Figure S2. The corA-like region amplified in all isolates. A search of the four $P$. syringae pv. actinidiae genomes included in this study revealed that the effector hopBl is not present in any of these isolates. Ferrante and Scortichini (19) also use the name avrAE1 for one of the avirulence effector genes for which they provide primer sequences. We believe this is a typographical mistake, and that the gene should have been labeled avrE1. A search of both GenBank and the Pseudomonas syringae Genome Resources Hops Database (http://www.pseudomonas-syringae. org/T3SS-Hops.xls) reveals that there is no effector gene called avrAE1, and a BLAST search of sequences amplified with the avrAE1 primers reveals significant homology (>90\%) with avrE1 effector genes sequenced from other $P$. syringae pathovars. Therefore, we refer to this gene as avrE1 throughout this article.

Of the 10 effector genes tested, four (avrPtol, hopC1, hopF2, and hopG1) were not detected in any $P$. syringae pv. actinidiae isolate (and were not present in the four published $P$. syringae pv. actinidiae genome sequences), three (avrE1, hrpK1, and hopAN1) were amplified in all isolates, and three (avrDl, hopAl, and hopAF1) showed variable patterns of amplification between isolates (Table 2). Genetic variation between isolates was detected for all six effector genes present in some or all $P$. syringae pv. actinidiae isolates (Fig. 4), and the same four MLSA groups as were detected via housekeeping gene variation were resolved via sequencing of effector genes. Psa3 and Psa4 could be differentiated both by genetic variation within the four effectors shared by both $P$. syringae pv. actinidiae MLSA groups and by effector

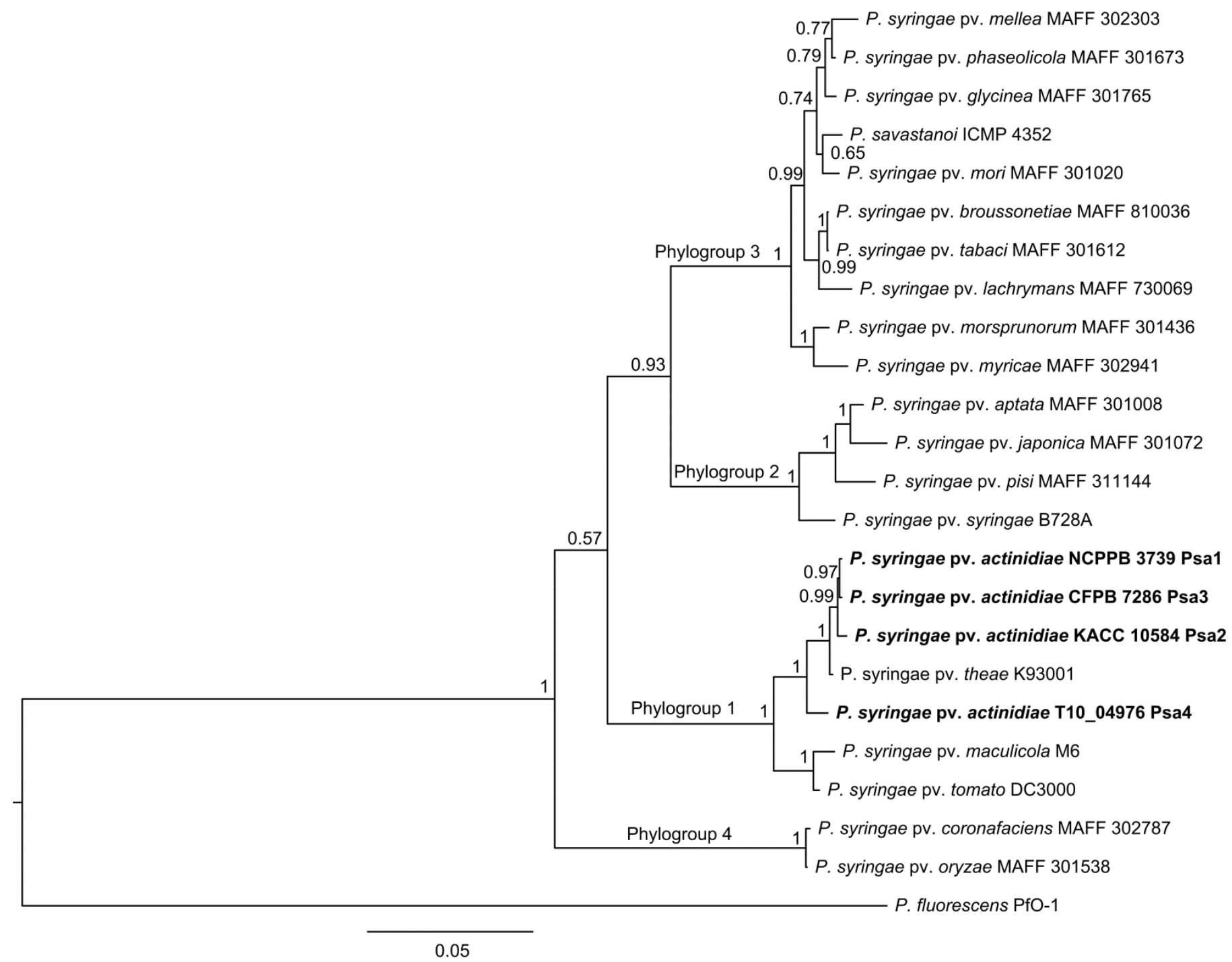

Fig. 3. Bayesian inference phylogenetic tree of selected Pseudomonas syringae pathovars (41), showing their relationship to $P$. syringae pv. actinidiae. Posterior probabilities are shown for selected nodes. Each gene partition was modeled separately and run for $1 \times 10^{7}$ generations. Clade posterior probabilities are shown above nodes and the scale bar indicates expected number of changes per site. 
gene presence or absence, whereby avrD1 is present in Psa3 but not Psa4, while hopAFl is present in Psa4 but not Psa3 (Table 2; Fig. 4). Psa4 is the only $P$. syringae pv. actinidiae population for which the effector avrD1 is absent (Table 2). Similarly, Psa2 (Korean) isolates could be differentiated by effector gene presence or absence, whereby hopAFl was present in two isolates (KACC 10584 and KACC 10754) but not a third (KACC 10594); as well as genetic variation within one of the six shared effectors (avrD1; two SNPs across 579 bp differentiate KACC10594 from the other two Korean isolates at this gene).

We assessed the presence of nonsynonymous substitutions in the four genetically variable nonhousekeeping genes present in all $P$. syringae pv. actinidiae isolates; namely hopAN1, corA-like, hrpK1, and avrE1. hopAN1 did not have any nonsynonymous substitutions, whereas the other three genes did. For corA-like, three nonsynonymous substitutions differentiate the Psa3 isolates from all other isolates. The $\mathrm{Ka} / \mathrm{Ks}_{\mathrm{MA}}$ ratio for corA-like was 0.26 $(P=0.11)$. For $h r p K 1$, three nonsynonymous substitutions differentiate the Psa4 isolates from all other isolates. The $\mathrm{Ka} / \mathrm{Ks}_{\mathrm{MA}}$ ratio for $h r p K 1$ was $0.06(P<0.001)$. For $a v r E 1,15$ nonsynonymous substitutions differentiated Psa4 from all other isolates. Two indels also occur in the amplicon, the first being a six-residue deletion in Psa4 and the second being a five-residue insertion in Psa4, with respect to the Psa1, Psa2, and Psa3 amino acid sequences (Supplemental Figure S3A). The $\mathrm{Ka} / \mathrm{Ks}_{\mathrm{MA}}$ ratio for $a v r E 1$ (after removal of indels) was $0.33(P=0.001)$. The amplified fragment was part of transcriptional unit III, one of two transcriptional units essential for avrEl gene function (28). Both alleles are similar to those found in other $P$. syringae pathovars, with the alleles found in Psa1, Psa2, and Psa3 being similar to that found in P. syringae pv. morsprunorum, while the Psa4 allele is similar to two P. syringae pv. tomato strains (Max13 and T1). Two other P. syringae pv. tomato strains (DC3000 and PT23) have alleles that share similarities with both the Psa3 and Psa4 alleles, whereby they share the Psa4 deletion but not the Psa4 insertion.

Phytotoxin gene detection. The coronatine gene was detected in all three Psa2 (Korean) isolates, and sequencing revealed that all three isolates were genetically identical for the portion of this gene amplified with the CFLF and CFLR coronatine primers. Isolates from New Zealand, Australia, Italy, Chile, and Japan did not amplify with the CFLF and CFLR primers, indicating that the gene for this toxin is not present in Psa1, Psa3, and Psa4 isolates (Table 2). Similarly, a BLAST search of the four published genome sequences with the Korean coronatine amplicon did not produce any hits. Presence of phaseolotoxin was tested using three sets of primers (Table 2), all of which provided complementary evidence that the phaseolotoxin gene is present only in Psa1 (Japanese and Italy 1992 outbreak) isolates (Table 2). Sequencing of the phaseolotoxin amplification products in Psa1 isolates was not undertaken during this study.

\section{DISCUSSION}

The genetic analyses conducted here show that $P$. syringae pv. actinidiae is a genetically heterogeneous and widely distributed pathogen. In total, we detected four distinct $P$. syringae pv. actinidiae MLSA groups worldwide and have named these groups or populations Psa1 for the P. syringae pv. actinidiae population present in Japan and Italy (1992 outbreak); Psa2 for the $P$.

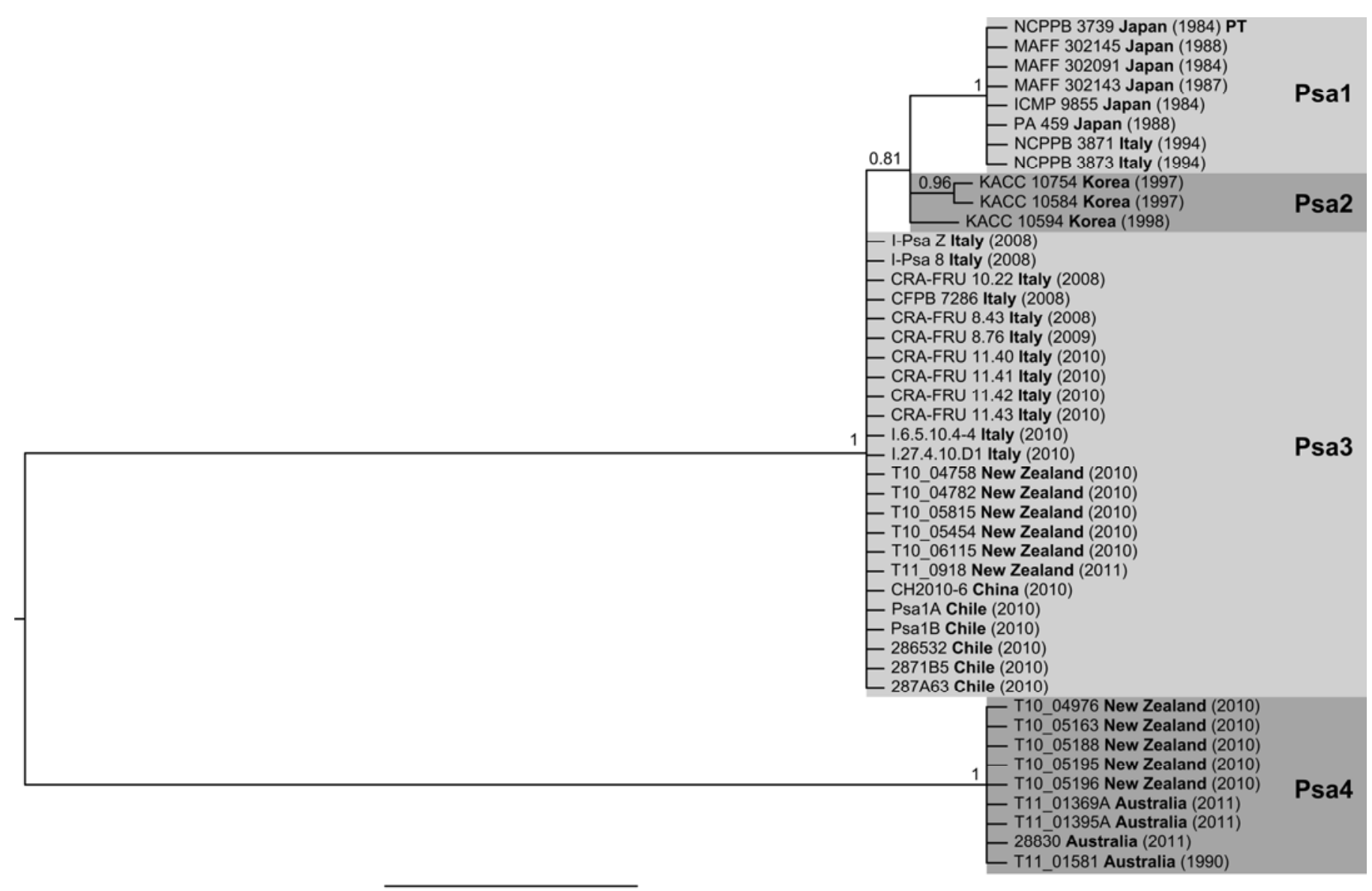

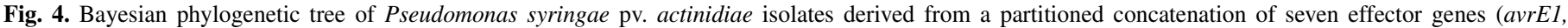

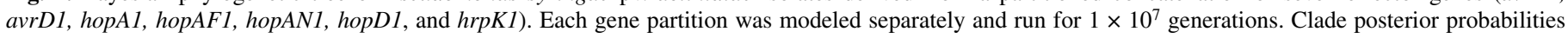
are shown above nodes and the scale bar indicates expected number of changes per site. 
syringae pv. actinidiae population present in Korea; Psa3 for the population of $P$. syringae pv. actinidiae currently present in the Ravenna and Latina regions of Italy (2008-09 outbreak), the Te Puke region of New Zealand, the O'Higgins and Maule regions of Chile, and the Shaanxi province of China; and Psa4 for the population of $P$. syringae pv. actinidiae present across New Zealand and in Australia (Victoria and Western Australia). Our approach allowed for an improved resolution of $P$. syringae pv. actinidiae populations than has been previously achieved with more limited genetic characterization $(47,49)$, by differentiating isolates from Japan and Korea into two MLSA groups. Furthermore, we found low levels of genetic heterogeneity within both Japan (housekeeping gene variation only: two SNPs across 8,271 bp $=0.02 \%$ sequence divergence among isolates) (Fig. 2) and Korea (housekeeping and effector gene variation: three SNPs across 8,271 bp = $0.04 \%$ sequence divergence among isolates) (Figs. 2 and 4). Further work is required to establish the extent of genetic and pathogenic differentiation of $P$. syringae pv. actinidiae populations within these two countries, and whether other $P$. syringae pv. actinidiae populations are now present in these countries, given that 15 to 28 years have passed since these Asian isolates were collected (Table 1). We have named the four P. syringae pv. actinidiae MLSA groups in the chronological order of their detection and, as more $P$. syringae pv. actinidiae populations are detected and characterized worldwide, it will be possible to easily fit them into this naming scheme. Various other names have been used to describe $P$. syringae pv. actinidiae populations, groups, or strains (Table 3 ), and a unified approach to naming $P$. syringae pv. actinidiae populations would help to reduce confusion.

Two P. syringae pv. actinidiae MLSA groups are present in New Zealand. The New Zealand Psa3 isolates are genetically identical, at 15 sequenced loci, to the highly damaging isolates first detected in the Latina and Ravenna regions of Italy in 200809, to the isolates first detected in Chile in 2010, and to a single isolate from China collected in 2010, suggesting a common evolutionary history. Isolates from France, Spain, and Portugal have also been found to belong to this same genetic lineage (32). On New Zealand kiwifruit orchards, Psa3 has been associated with progression from leaf spot symptoms to secondary symptoms, including production of exudates and cane and shoot dieback (16; J. L. Vanneste et al., unpublished data). Psa3 is currently largely restricted to the Bay of Plenty region of New Zealand, and management practices have been put in place to restrict the spread of this population both within and outside of affected areas. As of 9 July 2012, 37\% $(n=1,232)$ of New Zealand kiwifruit orchards were infected with Psa3, and $46 \%$ of New Zealand's kiwifruit hectares were on an orchard infected with Psa3 (http://www.kvh.org.nz/vdb/document/453). The Psa4 population is much more widespread in New Zealand (10; J. L. Vanneste et al., unpublished data) and has never been observed to progress beyond leaf spot symptoms, either in the field or under glasshouse conditions (J. L. Vanneste et al., unpublished data). Given that these symptoms mimic those caused by other Pseudo- monas spp. on kiwifruit, it is possible that this population has been present and undetected in New Zealand for some time, which could explain its widespread distribution. However, it is unlikely that the pathogen has been present in New Zealand for more than 15 years, because 83 Pseudomonas isolates in the ICMP and Plant and Food Research culture collections associated with kiwifruit and collected in New Zealand between 1971 and 1996 were screened with the Rees-George et al. (37) P. syringae pv. actinidiae-specific primers, and no isolates of $P$. syringae pv. actinidiae were found (35). Psa4 is present in Victoria, Australia and an archived isolate collected in Western Australia in 1990 was also identified as Psa4. Therefore, this population has been present in Australia for at least 20 years, and anecdotal evidence suggests that it has not caused vine or productivity losses in Western Australia since that time (14).

Psa4 is clearly genetically distinct, at 15 sequenced loci, from Psa1, Psa2, and Psa3. Phylogenetic analysis of housekeeping gene variation is the most appropriate to infer the evolutionary history of $P$. syringae pv. actinidiae isolates, because these genes have been shown to be transmitted vertically rather than horizontally $(21,40)$. Phylogenetic analysis of housekeeping genetic variation among $P$. syringae pv. actinidiae isolates and other $P$. syringae pathovars (Fig. 3) revealed that the pathovar $P$. syringae pv. theae is more similar to Psa1, Psa2, and Psa3 MLSA groups than any of these are to Psa4. Despite the genetic differences between Psa3 and Psa4, biochemical and pathogenicity testing of isolates from New Zealand orchards (Supplementary Information) (16; J. L. Vanneste et al., unpublished data) and comparisons with the $P$. syringae pv. actinidiae pathotype strain shows that both MLSA groups meet the current description of $P$. syringae pv. actinidiae (46). Psa3 and Psa4 are more genetically related to each other than to any other currently typed phylogroup I $P$. syringae pathovar, with the exception of $P$. syringae pv. theae (Fig. 3) (40). Further research will help to resolve the exact taxonomic relationships between the four $P$. syringae pv. actinidiae MLSA groups and $P$. syringae pv. theae.

A difference in pathogenicity of the Psa3 and Psa4 MLSA groups under glasshouse conditions in New Zealand has been detected (J. L. Vanneste et al., unpublished data). These differences are reflected in observations from the field, where progression to secondary symptoms such as canker formation and production of exudates has only been observed on orchards known to be infected with Psa3 (J. L. Vanneste et al., unpublished data). In New Zealand, the biosecurity response to $P$. syringae pv. actinidiae has focused on controlling the spread of Psa3, because it appears that, to date, Psa4 is not associated with aggressive symptoms in the field (J. L. Vanneste et al., unpublished data). Similarly, the fact that Psa4 has not caused economic losses in Australia despite being present for many years (14) would support our observations in New Zealand. The population here named Psa4 has been described as "Asian-like" (14) (Table 3) but this is not supported by the results presented here. The Asian MLSA groups Psa1 and Psa2 are more genetically similar to Psa3 (which

TABLE 3. Names used for Pseudomonas syringae pv. actinidiae populations since 2010

\begin{tabular}{|c|c|c|c|c|c|c|c|c|}
\hline Country & $\begin{array}{c}\text { Year of first } \\
\text { published } \\
\text { report }\end{array}$ & $\begin{array}{c}\text { This work } \\
\text { and EPPO } \\
(15)\end{array}$ & $\begin{array}{l}\text { Vanneste } \\
\text { et al. (49) }\end{array}$ & $\mathrm{KVH}^{\mathrm{a}}$ & $\begin{array}{l}\text { Chapman } \\
\text { et al. (10) }\end{array}$ & $\begin{array}{l}\text { Marcelletti } \\
\text { et al. (30) }\end{array}$ & Mazzaglia et al. (32) & EPPO (14) \\
\hline Japan & 1989 & Psa1 & cts haplotype A & $\ldots$ & $\ldots$ & J-Psa & Korean/Japanese lineage & $\ldots$ \\
\hline Italy & 1994 & Psa1 & cts haplotype A & $\ldots$ & $\ldots$ & I-Psa & Korean/Japanese lineage & $\ldots$ \\
\hline Korea & 1994 & Psa2 & cts haplotype A & $\ldots$ & $\ldots$ & $\ldots$ & Korean/Japanese lineage & $\ldots$ \\
\hline Italy & 2008 & Psa3 & cts haplotype I & $\ldots$ & Psa1 & I2-Psa & European/Chinese lineage & $\ldots$ \\
\hline $\mathrm{NZ}$ & 2011 & Psa3 & $\ldots$ & Psa-V & Psa1 & $\ldots$ & European/Chinese lineage & $\ldots$ \\
\hline NZ & 2011 & Psa4 & $\ldots$ & Psa-LV & Psa2 & $\ldots$ & $\ldots$ & $\ldots$ \\
\hline Chile & 2012 & Psa3 & $\ldots$ & $\ldots$ & $\ldots$ & $\ldots$ & $\ldots$ & $\ldots$ \\
\hline China & 2011 & Psa3 & $\ldots$ & $\ldots$ & $\ldots$ & $\ldots$ & European/Chinese lineage & $\ldots$ \\
\hline Australia & 2011 & Psa4 & $\ldots$ & $\ldots$ & $\ldots$ & $\ldots$ & $\ldots$ & Psa2, "Asian-like" \\
\hline
\end{tabular}

a Source: Kiwifruit Vine Health (http://www.kvh.org.nz/). 
is also found in Asia) than they are to Psa4, for the loci analyzed. The kiwifruit industry in New Zealand (Kiwifruit Vine Health) (Table 3) refers to Psa3 as Psa-V (for virulent) and Psa4 as PsaLV (for low virulence); however, the use of such phenotypic identifiers for bacterial populations is not useful in a wider context. Some authors have also used country letters to describe $P$. syringae pv. actinidiae populations, such as Psa-J for the Japanese population and Psa-I for the Italian population (30). However, we would argue that this scheme is open to confusion, because we have shown here that at least two of the $P$. syringae pv. actinidiae MLSA groups (Psa3 and Psa4) are found in several countries.

For the four genes for which $\mathrm{Ka} / \mathrm{Ks}$ ratios were ascertained, all had $\mathrm{Ka} / \mathrm{Ks}_{\mathrm{MA}}$ ratios of $<1$, suggesting that these genes are under purifying selection (selection against deleterious nonsynonymous substitutions) to conserve secondary structure. The effector gene avrE1 showed the greatest number of differences between Psa3 and Psa4 alleles (32 SNPs across the 477 bp amplified, of which 17 were synonymous and 15 were nonsynonymous, as well as two indels of 15 and $18 \mathrm{bp}$ ). Interestingly, avrE1 has been shown to have an important role in virulence in $P$. syringae pv. tomato. Lorang et al. (29) tested whether the avirulence genes $a v r A$, avrD, avrE, and avrPto were important for virulence on host plants. They found that $a v r E$ was particularly important, whereby $a v r E$ mutants had greatly reduced virulence and bacterial multiplication when compared with wild-type isolates. Badel et al. (2) have shown that avrE1 promotes lesion formation within plant cells, and that the combined actions of $a v r E 1$ and hopMl are particularly important in promoting bacterial growth in host (tomato) plants. Members of the avrE family of effectors are broadly conserved across gram-negative plant-pathogenic bacteria and have also been shown to have crucial roles in virulence in other bacterial genera (Erwinia and Pantoea) (20), and avrE has been found to be part of a core set of effectors in $P$. syringae, likely having been acquired before the diversification of pathovars (38). The amplified fragment of $a v r E 1$ consisted of transcriptional unit III, one of two units essential for gene function (28). Given the marked difference in DNA and amino acid sequence for the avrE1 gene between the Psa3 and Psa4 MLSA groups (including two indels) and the observed difference in virulence of these isolates on kiwifruit plants (J. L. Vanneste et al., unpublished data), this raises the interesting possibility that avrE1 also has an important role in $P$. syringae pv. actinidiae virulence, although more work is required to confirm this. It is also interesting to note that the effector hopAFl is missing from most $P$. syringae pv. actinidiae isolates tested here, being present only in Psa4 and two Korean isolates (KACC 10584 and KACC 10754). This effector has been identified as highly conserved across $P$. syringae pathovars, suggesting that it plays a central role in the disease process (41), possibly in suppressing flagellin-induced defenses of host plants (26). BLAST searches of the four published $P$. syringae pv. actinidiae genomes confirmed that hopAFl is also not present in these isolates.

By characterizing Psa3 and Psa4 isolates with a large set of genetic markers with differing evolutionary trajectories, we have been able to confirm that the observable differences in pathogenicity between these isolates (J. L. Vanneste et al., unpublished data) are underpinned by distinct genetic changes between the two MLSA groups. We have not detected any genetic differences between isolates within the Psa3 and Psa4 MLSA groups; whereas we have shown that several loci have high levels of SNPs differentiating the Psa3 and Psa4 MLSA groups, which may aid the development of robust diagnostic markers for future surveillance efforts. Indeed, it is possible to resolve all four MLSA groups by sequencing the $p f k$ gene alone. In New Zealand, genetic typing of unknown isolates is often achieved via sequencing of the three genes cts, gyrB, and hrpKl (10). The ability to rapidly and accurately diagnose $P$. syringae pv. actinidiae populations on infected orchards is crucial to management strategies aimed at containing the spread of this disease by allowing targeted control of the Psa3 population.

Genome sequencing has revealed that Psa1 and Psa2 form a genetic lineage separate from Psa3 (32). Our results support this observation, whereby analysis of genetic variation among housekeeping genes (MLSA analysis) revealed a closer genetic relationship between Psa1 and Psa2 isolates than these isolates had with Psa3 isolates. Interestingly, we also found that the same MLSA groups were reconstructed via sequencing of type III effector genes. These genes can undergo relatively rapid evolution via horizontal genetic exchange (21), although some members appear to be highly conserved among $P$. syringae pathovars and to evolve via descent (38). Our analysis included both rapidly (e.g., $a v r D 1$ ) and slowly (e.g., avrE1) evolving effector genes (38). Therefore, the fact that we found no differences in effector gene complement between Psa1, Psa2, and Psa3 isolates, and that the number of SNPs detected was of a similar magnitude to the number of SNPs observed in housekeeping genes, would suggest that all these isolates share a recent common ancestor. Psa3 appears to have a more rapidly recognizable phenotype than Psa1, Psa2, or Psa4, due to the rapid onset of secondary symptoms in kiwifruit plants infected with this pathogen. We also found no SNP differences among Psa3 populations from four different countries with a wide global distribution (Italy, New Zealand, Chile, and China). Conversely, we found genetic diversity within both Psa1 (two SNPs) and Psa2 (three SNPs), suggesting that these two populations have been extant for a longer time span than Psa3. Therefore, we hypothesize that the Psa3 population has evolved recently from either the Psa1 or Psa2 population, or from an as-yet uncharacterized $P$. syringae pv. actinidiae population (32). No isolate collected anywhere in the world before 2008 has been found to be Psa3. Similarly, Psa1 and Psa2 have not been detected since 1998, although this may be due to the dearth of recent $P$. syringae pv. actinidiae samples from Asia in international culture collections. It seems likely that the rapid evolution of a highly virulent strain of $P$. syringae pv. actinidiae occurred in situ within a single kiwifruit-growing region or country, and that the global spread of this population is a recent phenomenon, having occurred within the last 5 to 7 years. It has been proposed that China is the source country for Psa3; however, this observation was based on characterization of two identical isolates from one region in China (32). A much wider sampling of isolates from this country, as well as current sampling of other Asian kiwifruit-growing countries, will be required to confirm this supposition. It is unfortunate that historic isolates of $P$. syringae pv. actinidiae in China are not currently available in international culture collections, because such isolates could provide valuable insights into the form and rate of evolution of this damaging and economically important pathogen.

We have demonstrated that at least four P. syringae pv. actinidiae MLSA groups are present worldwide. One of these, Psa4, has not previously been described. Information about MLSA and effector gene diversity of $P$. syringae pv. actinidiae populations in New Zealand and overseas should provide a clearer picture of the phylogenetic relationships of this emergent disease in New Zealand and elsewhere, and may aid in the development of PCRbased assays to distinguish $P$. syringae pv. actinidiae isolates without the need for DNA sequencing.

\section{ACKNOWLEDGMENTS}

B. S. Weir was supported by the Ministry of Science and Innovation through the Defining New Zealand's Land Biota Biosystematics contract. We thank V. Caro (Servicio Agrícola y Ganadero, Ministerio de Agricultura, Chile) for providing isolates of Chilean P. syringae pv. actinidiae, D. Guttman and P. Rainey for providing expertise in the initial stages of the study, D. Tanner and other staff from Zespri for industry liaison, and 
the many people involved in collecting and processing kiwifruit leaves during the $P$. syringae pv. actinidiae response.

\section{LITERATURE CITED}

1. Abelleira, A., López, M. M., Peñalver, J., Aguín, O., Mansilla, J. P., Picoaga, A., and García, M. J. 2011. First report of bacterial canker of kiwifruit caused by Pseudomonas syringae pv. actinidiae in Spain. Plant Dis. 95:1583.

2. Badel, J. L., Shimizu, R., Oh, H.-S., and Collmer, A. 2006. A Pseudomonas syringae pv. tomato avrE1/hopM1 mutant is severely reduced in growth and lesion formation in tomato. Mol. Plant-Microbe Interact. 19:99-111.

3. Balestra, G. M., Mazzaglia, A., Quattruci, A., Renzi, M., and Rossetti, A. 2009. Current status of bacterial canker spread on kiwifruit in Italy. Australas. Plant Dis. Notes 4:34-36.

4. Balestra, G. M., Mazzaglia, A., Spinelli, R., Graziani, S., Quattrucci, A., and Rossetti, A. 2008. Bacterial canker on Actinidia chinensis (Cancro batterico su Actinidia chinensis). Inf. Agrar. 38:75-76.

5. Balestra, G. M., Renzi, M., and Mazzaglia, A. 2010. First report of bacterial canker of Actinidia deliciosa caused by Pseudomonas syringae pv. actinidiae in Portugal. New Dis. Rep. 22:10.

6. Bastas, K. K., and Karakaya, A. 2012. First report of bacterial canker of kiwifruit caused by Pseudomonas syringae pv. actinidiae in Turkey. Plant Dis. 96:452.

7. Bender, C. L., Alarcón-Chaidez, F., and Gross, D. C. 1999. Pseudomonas syringae phytotoxins: mode of action, regulation and biosynthesis by peptide and polyketide synthetases. Microbiol. Mol. Biol. Rev. 63:266292.

8. Bull, C. T., Clarke, C. R., Cai, R., Vinatzer, B. A., Jardini, T. M., and Koike, S. T. 2011. Multilocus sequence typing of Pseudomonas syringae sensu lato confirms previously described genomospecies and permits rapid identification of $P$. syringae pv. coriandricola and $P$. syringae pv. apii causing bacterial leaf spot on parsley. Phytopathology 101:847-858.

9. Chang, J. H., Urbach, J. M., Law, T. F., Arnold, L. W., Hu, A., Gombar, S., Grant, S. R., Ausubel, F. M., and Dangl, J. L. 2005. A highthroughput, near-saturating screen for type III effector genes from Pseudomonas syringae. Proc. Natl. Acad. Sci. USA 102:2549-2554.

10. Chapman, J., Taylor, R., and Alexander, B. 2011. Second Report on Characterisation of Pseudomonas syringae pv. actinidiae (Psa) isolates in New Zealand. Ministry of Agriculture and Forestry.

11. Cheng, H., Li, Y., Wan, S., Zhang, J., Ping, Q., Li, G., and Xing, J. 1995. Pathogenic identification of kiwifruit bacterial canker in Anhui. J. Anhui University, unpaginated. http://en.cnki.com.cn/Article_en/CJFDTOTALANHU503.006.htm

12. EPPO. 2011. First report of Pseudomonas syringae pv. actinidiae in Switzerland. Number 8, 2011/168. http://archives.eppo.org/EPPOReporting/2011/Rse-1108.pdf

13. EPPO. 2011. First report of Pseudomonas syringae pv. actinidiae in Chile. Number 3, 2011/055. http://archives.eppo.org/EPPOReporting/2011/Rse-1103.pdf

14. EPPO. 2011. First report of Pseudomonas syringae pv. actinidiae in Australia. Number 6, 2011/130. http://archives.eppo.org/EPPOReporting/2011/Rse-1106.pdf

15. EPPO. 2011. Express Pest Risk Analysis for Pseudomonas syringae pv. actinidiae. EPPO Report 11-17237. http://www.ersa.fvg.it/istituzionale/ servizio-fitosanitario-chimico/circa/organismo-nocivo/batteri/pseudomonas-syringae-pv-actinidiae/pest-risk-analisys/EPPO\%20Draft_Express_PRA.docx

16. Everett, K. R., Taylor, R. K., Romberg, M. R., Rees-George, J. R. G., Fullerton, R., Vanneste, J. L., and Manning, M. A. 2011. First report of Pseudomonas syringae pv. actinidiae causing kiwifruit bacterial canker in New Zealand. Australas. Plant Dis. Notes 6:67-71.

17. Ferrante, P., Clarke, C. R., Cavanaugh, C. A., Michelmore, R. W., Buonaurio, R., and Vinatzer, B. 2009. Contributions of the effector gene hopQ1-1 to differences in host range between Pseudomonas syringae pv. phaseolicola and P. syringae pv. tabaci. Mol. Plant Pathol. 10:837-842.

18. Ferrante, P., and Scortichini, M. 2009. Identification of Pseudomonas syringae pv. actinidiae as causal agent of bacterial canker of yellow kiwifruit (Actinidia chinensis Planchon) in Central Italy. J. Phytopathol. 157:768-770

19. Ferrante, P., and Scortichini, M. 2010. Molecular and phenotypic features of Pseudomonas syringae pv. actinidiae isolated during recent epidemics of bacterial canker on yellow kiwifruit (Actinidia chinensis) in central Italy. Plant Pathol. 59:954-962.

20. Ham, J. H., Majerczak, D. R., Nomura, K., Mecey, C., Uribe, F., He, S.Y., Mackey, D., and Coplin, D. L. 2009. Multiple activities of the plant pathogen type III effector proteins WtsE and AvrE require WxxxE motifs. Mol. Plant-Microbe Interact. 22:703-712.
21. Hwang, M. S. H., Morgan, R. L., Sarkar, S. F., Wang, P. W., and Guttman, D. S. 2005. Phylogenetic characterization of virulence and resistance phenotypes of Pseudomonas syringae. Appl. Environ. Microbiol. 71:5182-5191.

22. King, E. O., Ward, M. K., and Raney, D. E. 1954. Two simple media for the demonstration of pyocyanin and fluorescein. J. Lab. Clin. Med. 44:301-307.

23. Koh, Y., and Lee, D. 1992. Canker of kiwifruit by Pseudomonas syringae pv. morsprunorum. Korean J. Plant Pathol. 8:119-122.

24. Koh, Y., and Nou, I. 2002. DNA markers for identification of Pseudomonas syringae pv. actinidiae. Mol. Cells 13:309-314.

25. Koh, Y. J., Cha, B. J., Chung, H. J., and Lee, D. H. 1994. Outbreak and spread of bacterial canker in kiwifruit. Korean J. Plant Pathol. 10:68-72.

26. Li, X., Lin, H., Zhang, W., Zou, Y., Zhang, J., Tang, X., and Zhou, J.-M. 2005. Flagellin induces innate immunity in nonhost interactions that is suppressed by Pseudomonas syringae effectors. Proc. Natl. Acad. Sci. USA 102:12990-12995.

27. Lindeberg, M., Stavrinides, J., Chang, J. H., Alfano, J. R., Collmer, A., Dangl, J. L., Greenberg, J. T., Mansfield, J. W., and Guttman, D. S. 2005. Proposed guidelines for a unified nomenclature and phylogenetic analysis of type III hop effector proteins in the plant pathogen Pseudomonas syringae. Mol. Plant-Microbe Interact. 18:275-282.

28. Lorang, J. M., and Keen. N. T. 1995. Characterization of avrE from Pseudomonas syringae pv. tomato: An hrp-linked avirulence locus consisting of at least two transcriptional units. Mol. Plant-Microbe Interact. 8:49-57.

29. Lorang, J. M., Shen, H., Kobayashi, D., Cooksey, D., and Keen, N. T. 1994. avrA and avrE in Pseudomonas syringae pv. tomato PT23 play a role in virulence on tomato plants. Mol. Plant-Microbe Interact. 7:505-515.

30. Marcelletti, S., Ferrante, P., Petriccione, M., Firrao, G., and Scortichini, M. 2011. Pseudomonas syringae pv. actinidiae draft genomes comparison reveal strain-specific features involved in adaptation and virulence to Actinidia species. PLoS One 6:e27297.

31. Mazzaglia, A., Renzi, M., and Balestra, G. M. 2011. Comparison and utilization of different PCR-based approaches for molecular typing of Pseudomonas syringae pv. actinidiae strains from Italy. Can. J. Plant Pathol. 33:8-18.

32. Mazzaglia, A., Studholme, D. J., Taratufolo, M. C., Cai, R., Almeida, N. F., Goodman, T., Guttman, D. S., Vinatzer, B. A., and Balestra, G. M. 2012. Pseudomonas syringae pv. actinidiae (PSA) isolates from recent bacterial canker of kiwifruit outbreaks belong to the same genetic lineage. PLoS One 7:e36518.

33. Maiden, M. C. J., Bygraves, J. A., Feil, E., Morelli, G. Russell, J. E., Urwin, R., Zhang, Q., Zhou, J., and Zurth, K. et al. 1998. Multilocus sequence typing: A protable approach to the identification of clones within populations of pathogenic microorganisms. Proc. Natl. Acad. Sci. 95:3140-3145.

34. Nylander, J. A. A. 2004. MrModeltest v2. Program distributed by the author. Evolutionary Biology Centre, Uppsala University.

35. Park, D., Than, D., Everett, K., Rees-George, J., Romberg, M. K., and Alexander, B. J. R. 2011. Screening of historical isolates stored in New Zealand culture collections for Pseudomonas syringae pv. actinidiae. N. Z. Plant Prot. 64:292.

36. Parkinson, N., Bryant, R., Bew, J., and Elphinstone, J. 2011. Rapid phylogenetic identification of members of the Pseudomonas syringae species complex using the rpoD locus. Plant Pathol. 60:338-344.

37. Rees-George, J., Vanneste, J. L., Cornish, D. A., Pushparajah, I. P. S., Yu, J., Templeton, M. D., and Everett, K. R. 2010. Detection of Pseudomonas syringae pv. actinidiae using polymerase chain reaction (PCR) primers based on the 16S-23S rDNA intertranscribed spacer region and comparison with PCR primers based on other gene regions. Plant Pathol. 59:453-464.

38. Rohmer, L., Guttman, D. S., and Dangl, J. L. 1994. Diverse evolutionary mechanisms shape the type III effector virulence factor repertoire in the plant pathogen Pseudomonas syringae. Genetics 167:1341-1360.

39. Ronquist, F., Teslenko, M., van der Mark, P., Ayres, D., Darling, A., Höhna, S., Larget, B., Liu, L., Suchard, M. A., Huelsenbeck, J. P. 2012. MrBayes 3.2: Efficient Bayesian phylogenetic inference and model choice across a large model space. Syst. Biol. 61:539-542.

40. Sarkar, S., and Guttman, D. 2004. The evolution of the core genome of Pseudomonas syringae, a highly clonal, endemic plant pathogen. Appl. Environ. Microbiol. 70:1999-2012.

41. Sarkar, S. F., Gordon, J. S., Martin, G. B., and Guttman, D. S. 2006. Comparative genomics of host-specific virulence in Pseudomonas syringae. Genetics 174:1041-1056.

42. Scortichini, M. 1994. Occurrence of Pseudomonas syringae pv. actinidiae on kiwifruit in Italy. Plant Pathol. 43:1035-1038.

43. Scortichini, M., Marchesi, U., and Di Prospero, P. 2002. Genetic relatedness among Pseudomonas avellanae, P. syringae pv. theae and P.s. pv. actinidiae, and their identification. Eur. J. Plant Pathol. 108:269-278. 
44. Serizawa, S., Ichikawa, T., Takikawa, Y., Tsuyumu, S., and Goto, M. 1989. Occurrence of bacterial canker of kiwifruit in Japan: description of symptoms, isolation of the pathogen and screening of bactericides. Ann. Phytopathol. Soc. Jpn. 55:427-436.

45. Shim Han, H., Jung Oak, E., Jin Koh, Y., Hur, J.-S., and Sung Jung, J. 2003. Characterization of Pseudomonas syringae pv. actinidiae isolated in Korea and genetic relationship among coronatine-producing pathovars based on $\mathrm{cmaU}$ sequences. Acta Hortic. 610:403-408.

46. Takikawa, Y., Serizawa, S., Ichikawa, T., Tsuyumu, S., and Goto, M. 1989. Pseudomonas syringae pv. actinidiae sp. nov.: the causal bacterium of canker in kiwifruit in Japan. Ann. Phytopathol. Soc. Jpn. 55:437-444.

47. Vanneste, J. L., Kay, C., Onorato, R., Yu, J., Cornish, D. A., Spinelli, F., and Max, S. 2011. Recent advances in the characterisation and control of Pseudomonas syringae pv. actinidiae, the causal agent of bacterial canker on kiwifruit. Acta Hortic. 913:443-455.
48. Vanneste, J. L., Poliakoff, F., Audusseau, C., Cornish, D. A., Paillard, S., Rivoal, C., and Yu, J. 2011. First report of Pseudomonas syringae pv. actinidiae, the causal agent of bacterial canker on kiwifruit in France. Plant Dis. 95:1311.

49. Vanneste, J. L., Yu, J., and Cornish, D. A. 2010. Molecular characterisations of Pseudomonas syringae pv. actinidiae strains isolated from the recent outbreak of bacterial canker on kiwifruit in Italy. N. Z. Plant Prot. 63:7-14.

50. Wang, Z., Tang, X., and Liu, S. 1992. Identification of the pathogenic bacterium for bacterial canker on Actinidia in Sichuan. J. Southwest Agricultural University, unpaginated. http://en.cnki.com.cn/Article_en/ CJFDTOTAL-XNND199206007.htm

51. Zhang, Z., Li, J., Zhao, X.-Q., Wang, J., Wong, G. Q.-S., and Yu, J. 2006. KaKs_Calculator: Calculating $\mathrm{Ka}$ and $\mathrm{Ks}$ through model selection and model averaging. Genomics Proteomics Bioinf. 4:259-263. 